Article

\title{
Sustainability: Nutrition and Dietetic Students' Perceptions
}

\author{
Sarah Burkhart ${ }^{1, *(\mathbb{C}}$, Michele Verdonck ${ }^{1}$, Theresa Ashford ${ }^{2} \mathbb{C}$ and Judith Maher ${ }^{1}$ \\ 1 School of Health and Sport Sciences, University of the Sunshine Coast, Maroochydore DC, Queensland 4557, \\ Australia; michele.verdonck@usc.edu.au (M.V.); jmaher@usc.edu.au (J.M.) \\ 2 School of Social Science, University of the Sunshine Coast, Maroochydore DC, Queensland 4557, Australia; \\ tashford@usc.edu.au \\ * Correspondence: sburkhar@usc.edu.au; Tel.: +61-7-5456-5046
}

Received: 28 November 2019; Accepted: 31 January 2020; Published: 3 February 2020

\begin{abstract}
Opportunities exist for nutrition and dietetic (N\&D) professionals to contribute to sustainable development and support actions towards the attainment of the UN's Sustainable Development Goals (SGD's). Students undertaking higher education are well-placed to develop skills and capabilities in creative and critical problem solving for sustainability. However, there is limited literature exploring nutrition and dietetic students' perceptions of sustainability that would help to inform an effective and constructively aligned embedding of sustainability content and active learning opportunities into curriculum. This descriptive cohort study design utilised a 17-question online survey to explore 95 Australian N\&D undergraduate students' self-reported familiarity with and perceived importance of sustainability and related concepts, and view of sustainability for future practice. Participants reported being more familiar with the term environmental sustainability and related concepts than economic or social sustainability. Varying levels of familiarity of 42 sustainability related concepts within economic resilience, environmental integrity, social development and cross-cutting issues were reported. Most participants $(82 \%, \mathrm{n}=78)$ reported sustainability was very important in general $(82 \%, n=78)$, and for professional practice $(63 \%, n=60)$. Over half of the participants identified government led initiatives to address the future of society $(65 \%, n=71)$. Our study highlights the complexity of sustainability in a discipline specific context and the need for understanding students' perceptions of sustainability to inform N\&D curriculum design.
\end{abstract}

Keywords: undergraduate; sustainable development; environmental sustainability; social sustainability; economic sustainability; Australia; professional practice

\section{Introduction}

Sustainability, and sustainable development are emerging as central concepts within professional nutrition and dietetic practice [1,2]. This emergence runs parallel to calls in other disciplines and higher education itself to reposition our work within a new lens of the Anthropocene and further, for some a "climate emergency" [3]. The Anthropocene is a significant shift as it recognises this period as a point in geological time where human activities have become the dominant source of change on the physical systems of the earth. This recognition highlights the critical importance of sustainability thinking and sustainable development. The Sustainable Development Goals (SDGs), adopted in 2015 by all United Nations Member States, include several dimensions that directly relate to either food production, consumption, access and distribution on the planet (i.e., SDG 2, 6, and 11-13). The SDGs demonstrate that social, economic and environmental systems are interrelated and in order to promote sustainable development we need to develop creative, ethical and competent thinkers. Clearly there are significant opportunities for nutrition and dietetic $(N \& D)$ professionals to contribute to the achievement of the 
SDGs and sustainable development in general. Harmon et al. suggest that educators in N\&D should integrate sustainability thinking into curriculum and learning activities in order to "further develop future nutritionists and dietitians to be leaders and advocates for food system practices that facilitate a healthy planet and healthy humans" (p. 1210) [2]. With this challenge in hand, this research seeks to determine the level of understanding current students have of sustainability concepts and applications in order to build a discipline specific curriculum that is more holistic and embeds the content and competencies required to address the SDGs.

Students undertaking higher education, as the future professional workforce, are in an ideal position to develop skills and capabilities in creative and critical problem solving for sustainability. Although Kagawa [4], Bollani [5] and Sidiropoulos [6] have explored perceptions of sustainability among students within higher education, there is little that explores $N \& D$ student perspectives in particular, and none that explores their holistic understanding of sustainability. Understanding how $N \& D$ undergraduate students perceive sustainability is important as these students will likely be called upon to consider elements of sustainability within the food system and nutrition practice in future work. Understanding student perceptions of sustainability provides insight into their views and attitudes, and allows curriculum developers to harness areas of strength, address gaps and design required re-alignments in understanding. Mohamedbhai states in his forward to Higher Education and Sustainable Development [7] that teaching sustainable development in disciplines "requires adopting a multi-disciplinary and holistic approach, encouraging teamwork, promoting creativity and innovation, and developing critical and systems thinking in students". Therefore sustainability thinking does not emerge serendipitously but must be reflected in explicit pedagogical approaches and targeted educational strategies $[6,8]$.

In the current 'post truth' environment there is a possibility of a greater divergence in understanding of key issues such as climate change, human responsibility and sustainability [9]. Moreover, a clear understanding of how Australian N\&D students perceive the importance of sustainability in practice and whether and to what extent nutrition and dietetic students are engaging personally with sustainability-related action is not available. This knowledge can inform a learner-centred discipline tailored curriculum design to embed sustainability thinking. As such, the aim of this descriptive cohort study was to explore undergraduate students self-reported familiarity with and perceived importance of sustainability and related concepts; and views of sustainability in their future practice and whether and to what extent nutrition and dietetic students are engaging personally with sustainability-related action.

\section{Materials and Methods}

A descriptive cohort study design was used to explore nutrition and dietetic undergraduate students' self-reported familiarity with and perceived importance of sustainability and related concepts, and view of sustainability for future practice. Ethical approval was provided by the Human Research Ethics Committee of the authors' institution (A16837).

\subsection{Data Collection}

Students' self-reported familiarity, importance and view for future practice were measured using a 17-question online questionnaire administered using Survey Monkey. Five questions asked about participant characteristics (sex, age range, enrolment status (fulltime or part-time), program of enrolment and level of the university courses they are currently studying).

The following were measured on a five-point Likert scale; 1. Familiarity with the terms; sustainability, environmental sustainability, social sustainability and economic sustainability (not at all familiar to very familiar); 2 . Familiarity with 42 sustainability related concepts $[2,10]$ grouped within the categories of social development (e.g., social justice in the food system), environmental integrity (e.g., use of synthetic chemicals and pesticides), economic resilience (e.g., resilience to economic risk) and cross-cutting issues (e.g., the use of food and agricultural policies) (not at all familiar to very familiar) (provided in one question); 3 . Degree to which they believed that sustainability is an important 
issue in general (very unimportant to very important); 4 . Degree to which sustainability influences the decisions they make daily (not at all to all of the time); and 5. Importance of sustainability for future practice as a nutritionist or dietitian (very unimportant to very important). In addition, students were asked how they would describe their attitude towards sustainability on a descriptive scale from I think it is a waste of time and effort to I am a passionate advocate [4]. Students personal view of the future of society was measured using the question "which of the following options most closely represents your personal view of society?" [4]. Questions not taken from existing literature were developed by consensus of the research team.

A pilot of the survey was undertaken in July 2016 with a small sample $(n=4)$ of N\&D students. Minor changes were made to wording of some questions based on the pilot. During August and September 2016, potential participants (383 students who were enrolled in either the Bachelor of Nutrition or the Bachelor of Nutrition and Dietetics at the authors institution at the time of survey deployment) were invited to take part in the questionnaire through the University learning management system. Participation was voluntary and prior to completing the survey, students were asked to read a Project Information Sheet describing the collection and use of data. The survey took approximately 15 min to complete and consent was implied through completion. On completion of the questionnaire students could elect to be included in a random draw for one of six $\$ 50$ honorariums. This information was collected separately to the questionnaire response.

\subsection{Data Analysis}

Data was analysed descriptively using SPSS (SPSS version 24, SPSS Inc., Chicago, IL, 2016) to present self-reported findings. Responses to questions regarding familiarity (general terms and sustainability related concepts), importance in general and for future practice, and degree to which sustainability influences daily decisions were summarised with proportions for each level of the five-point Likert scale. Responses to questions regarding attitude towards sustainability and personal view of the future were summarised with proportions of each of the questions' four possible responses.

\section{Results}

\subsection{Participant Characteristics}

A total of 95 students enrolled in either a Bachelor of Nutrition $(n=32,34 \%)$ or a Bachelor of Nutrition and Dietetics $(n=63,66 \%)$ at a regional Australian University completed the survey (response rate $=25 \%$ ). Just over half of the participants were aged $18-25$ years $(n=54,57 \%)$, with the majority female $(\mathrm{n}=86,91.5 \%)$. Two thirds of the participants reported that most courses they were completing were at first $(n=35,37 \%)$ or second $(n=29,30.5 \%)$ year level, with most $(n=73,77.7 \%)$ enrolled fulltime.

\subsection{Importance of, and Familiarity with Sustainability}

A total of $82 \%$ of students $(n=78)$ reported that sustainability in general is a very important issue, with $17 \%$ reporting important and $1 \%$ somewhat important. Most students reported that sustainability was a very important $(n=60,63 \%)$ or important $(n=28,29.5 \%)$ issue for their future practice as a nutritionist or dietitian.

The majority (97\%) of students reported being familiar ( $n=22,23 \%)$, quite familiar $(n=43,45 \%)$ or very familiar $(n=27,28 \%)$ with the term sustainability. A greater proportion of students were very or quite familiar with the term environmental sustainability $(75 \%)$, compared to economic $(47 \%)$ and social (22\%) sustainability (Figure 1 ). 


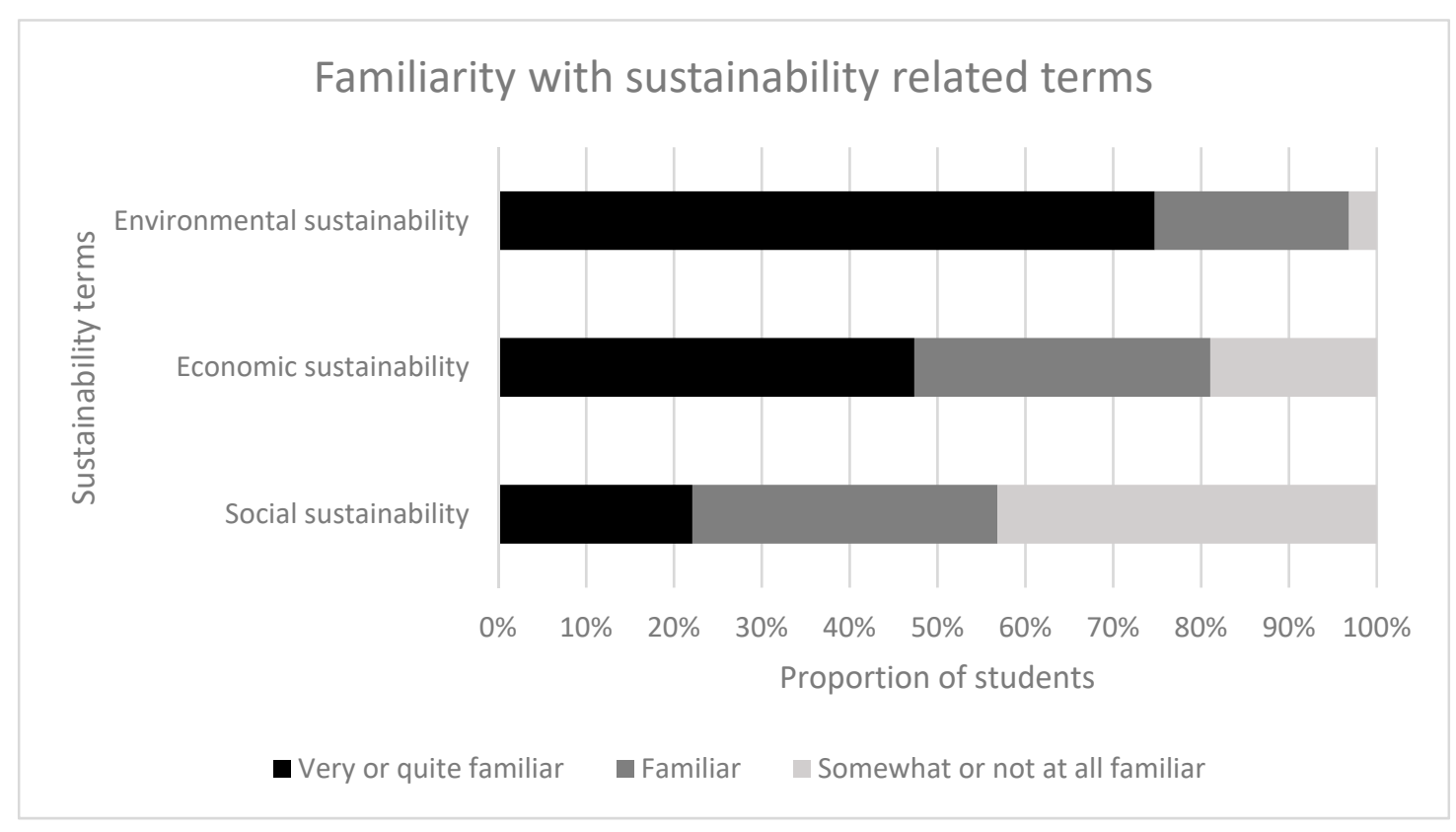

Figure 1. Students self-report familiarity with sustainability terms.

In general, when considering the 42 sustainability concepts students reported more familiarity with concepts of environmental integrity than concepts of social development, economic resilience and cross-cutting issues. Concepts that students reported being more familiar with (greater than $75 \%$ proportion being very/quite familiar) included the widespread availability of highly processed foods (90.5\%, environmental integrity), secure livelihoods (80\%, economic resilience), and relationship between food choices and the local economy (77.9\%, economic resilience). Conversely, sustainability concepts that students reported being less familiar with (more than $25 \%$ being somewhat/not at all familiar) were the use of food and agriculture policies (41.1\%), labour rights $(28.3 \%)$, issues related to food security at a national and global level $(27.4 \%)$, social justice in the food system $(25.3 \%)$ (all cross-cutting issues), living conditions of farm labourers (41.1.\%, social development), farmland protection (35.5\%, environmental integrity), and economic viability of the agriculture sector $(37.2 \%)$, resilience to economic risk (37.2\%), opportunity to contribute to local or global markets $(29.5 \%)$, preservation of rural communities (28.4\%) and social capital (27.4\%) (all economic resilience) (Figure 2). 


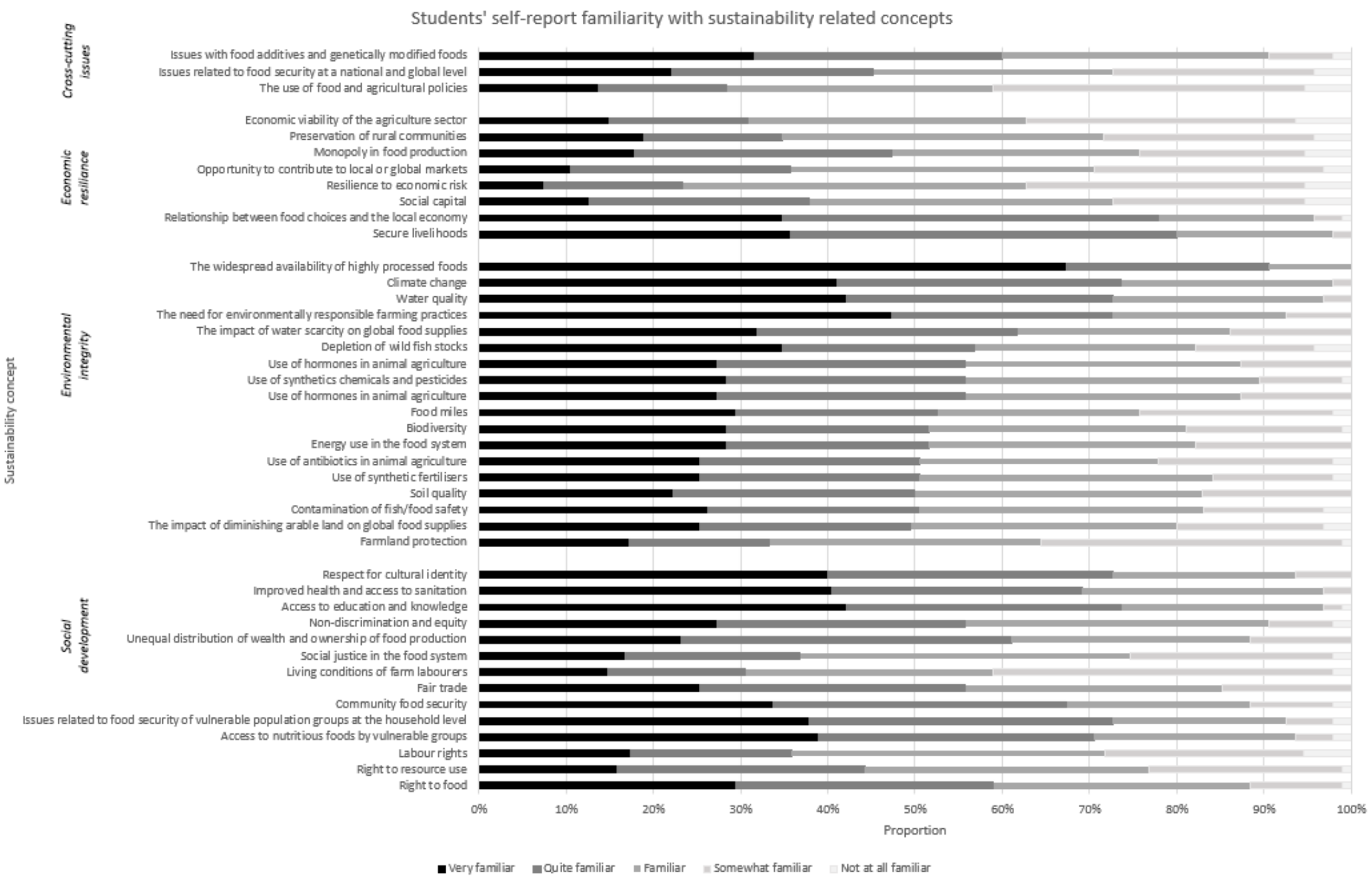

Figure 2. Students' self-report familiarity with sustainability related concepts. 


\subsection{Personal Attitudes and Behaviours Towards Sustainability}

A higher proportion of students reported that sustainability sometimes $(\mathrm{n}=38,40.4 \%)$ or often $(\mathrm{n}=36,38.3 \%$ ) influences their daily decisions, with less reporting all the time $(\mathrm{n}=11,11.7 \%)$, rarely $(\mathrm{n}=8,8.5 \%)$ and not at all $(\mathrm{n}=1,1.1 \%)$. Personal advocacy behaviours around sustainability were investigated (Table 1) which identified students as either active in addressing sustainability or passive but positive toward the issue. Predominantly respondents reported a perceived need for government led initiatives to address sustainability into the future (Tables 1 and 2).

Table 1. Student attitudes towards sustainability.

\begin{tabular}{cc}
\hline How Would You Describe Your Attitude Towards Sustainability? & n (\%) \\
\hline I am a passionate advocate & $26(27.7 \%)$ \\
I think it is a good thing & $64(68.1 \%)$ \\
It is OK if others want to do it & $3(3.2 \%)$ \\
I am not really bothered & $1(1.1 \%)$ \\
\hline
\end{tabular}

Table 2. Student personal views of sustainability.

\begin{tabular}{lc}
\hline Which One of the Following Most Closely Represents Your Personal View of the Future & n (\%) \\
of Society? & collapse of our social and economic systems \\
\hline $\begin{array}{l}\text { We are headed straight for ecological catastrophe and in my lifetime I will see the consequent } \\
\text { The best way forward is the formation of local economies of exchange centred around the } \\
\text { values of smallness, justice, eco-concern and living in voluntary simplicity }\end{array}$ & $11(11.6 \%)$ \\
\hline $\begin{array}{l}\text { Improved government policies about the environment, trade and social services combined } \\
\text { with a better educated youth will ensure a safe, healthy, sustainable society living with } \\
\text { ecological limits }\end{array}$ & $51(53.7 \%)$ \\
\hline $\begin{array}{l}\text { Only through strong government intervention will we be able to establish justice and equality } \\
\text { which will ensure a safe, healthy and sustainable society living within ecological issues }\end{array}$ & $20(21.1 \%)$ \\
\hline
\end{tabular}

\section{Discussion}

The aim of this descriptive cohort study was to explore undergraduate nutrition and dietetic students' self-reported familiarity with and perceived importance of sustainability and related concepts, and views of sustainability in their future practice. While there is international literature that examines undergraduate students' perceptions of sustainability in other disciplines, there is no such literature in the context of nutrition and dietetics.

Overall, Australian student participants were most familiar with environmental aspects of sustainability and viewed sustainability as an important issue for nutrition and dietetic practice. Student attitudes towards sustainability were generally positive and recognised the need for both personal and government leadership for the future of society.

Our study highlights that there is a general affinity and awareness of the importance of sustainability at a general level. However, this was a surface level appreciation. When more specific and detailed aspects or dimensions of sustainability were raised the knowledge and familiarity of this cohort decreased. This is a useful finding and indicates that core beliefs and values around sustainability exist, and that there are productive opportunities to leverage this interest into more specific applications in the N\&D curriculum. In the US, Harmon found that educators (77\%) believed students lack interest in sustainability [2], which is likely to influence the importance educators place on integrating sustainability into curriculum. However, much has changed in the last thirteen years with the Sustainable Development Goals and the Paris Agreement both coming into effect in 2015, and the most recent work by the Intergovernmental Panel on Climate Change (i.e., Special Report on Global Warming of $1.5^{\circ} \mathrm{C}$, 2018). 
Our findings mirror work produced by Kagawa in other student groups [4] in regard to reporting that sustainability was a "good thing" without the accompanying familiarity or understanding of applications of sustainability or sustainable development. In this research we did not link students' views with familiarity of sustainability, but we feel this warrants further investigation. Nonetheless this finding supports future initiatives to increase the scope and depth of sustainability in our N\&D programs.

We found that student familiarity with the broad category of environmental sustainability was the most significant. This is not a surprising outcome given the coverage of sustainability issues in both media (drought, flooding, fire, climate change) and in the links to environment within the N\&D curriculum, including food production systems, food system sustainability, food quality, waste and food miles literature which can be directly linked with the environment domain [10]. Some of the lack of familiarity with the specified concepts (Figure 2), which were based on those reported by Harmon [2] and Worsley [10], could be attributed to the fact that our students may not have come across these specific concept descriptors before (e.g., resilience to economic risk, social capital, monopoly of food production). In addition, they may have a limited understanding of the more technical concepts associated with the broader food system (e.g., policy, global markets, and food security). This raises the importance of using consistent language across courses to ensure these aspects are not just once off content occurrences. It suggests that embedding systems thinking and other key pedagogical approaches such as wicked problems, active learning and rich case studies which are contextualised within these larger frameworks will be important to deepen student understanding and increase familiarity with these cross-cutting issues [11]. Following the findings of Mintz and Tal [11], a holistic approach should be employed to foreground the relationships between sustainable development and the discipline of nutrition and dietetics.

It should also be recognised that these students may be demonstrating knowledge that precedes their university courses, and in some cases may have inspired students to choose nutrition and dietetics as a career pathway. This suggests that there is significant potential to build on this knowledge and interest with discipline specific content and competency development. Mintz and Tal suggest that motivation, which is a higher-order learning outcome, is related to how students become engaged and actively advocate for sustainability in their personal and professional lives. These findings suggest that this student cohort may be interested and motivated to deepen their understanding and awareness of sustainability models, frameworks, systems and applications of sustainability. This information should encourage academics teaching in this program to include connections to sustainability in their content and learning activities. The combination of key deficits of familiarity of sustainability related concepts (Figure 2) and the general positive attitude students have towards sustainability (Table 1) would indicate that a program curriculum mapping exercise to embed sustainability would be positively viewed by students.

Given the relationship between gender and views of sustainability reported by Kagawa [4] and Robertson [12], it would be interesting to look at this in N\&D students, however as our sample was predominately female (reflecting our overall N\&D cohort), this was not possible. While we found that over three-quarters of students in this cohort reported that sustainability influences their daily decisions, we did not investigate how this occurs, nor what importance students place on different concepts of sustainability. This warrants further investigation, particularly given that we found varying familiarity with concepts of sustainability and that work by Hawkins suggests that a personal commitment to sustainability as a lens is imperative for integration into practice [13].

Research around student engagement, self-belief and enjoyment in learning is extensive [14,15]. In our study, participants viewed sustainability as important for their future practice as dietitians or nutritionists, therefore this finding should support and leverage a deeper integration of sustainability themes and competencies into N\&D curriculum. Our results, however, suggest students are likely to be receptive to integrated curriculum that supports them to become sustainability aware/focused nutrition practitioners. 
Recent work in Australia has mapped food system sustainability, demonstrating a strong focus on environmental sustainability situations in N\&D curriculum [16]. This provides important information for educators but our research suggests that N\&D curriculum and professional competency training should also include the more challenging integration of environmental, social and economic sustainability into practice. Higher education educators are challenged to develop engaging and connected curriculum that builds knowledge, skills and competencies that will enable students to navigate and tackle the hyper complex and ethically imbued problems around sustainable development. This work is paramount and requires future graduates to meet the unprecedentedly challenged environmental, economic and social aspects of sustainability. There are several trajectories that this research can take with the recognition we are starting in a good place. This sample of Australian N\&D students recognise sustainability is important and are currently incorporating that knowledge into behaviours of advocacy or interest.

This investigation also included, but did not report in this article, academic and practitioner beliefs and values around sustainability. Academic and practitioner insights may assist in developing authentic student assessment that reflect the real-world complexity of sustainability in practice. Cotton et al. researched the link between academic knowledge and belief around sustainability and how academics incorporated this material into their curricular areas in the UK [17]. Issues that arose at that time, now 13 years past, were around issues of feasibility of embedding and concerns around teaching the moral and ethical (value-laden) considerations of sustainability [17].

There are several limitations to this study. Our sample only reflects N\&D students at our institution, a regional Australian University, and therefore has limited generalisability. Investigating students from a range of Universities within Australia and globally would help to determine if there is coherence amongst N\&D students as whole in Australia and internationally. We had more students from initial years of the program participate and we could not identify if progression through N\&D programs may impact familiarity with concepts of sustainability. Future work should explore changes in familiarity and views of sustainability based on student experiences of our renewed N\&D curriculum. Although the response rate for this study was modest, given the sampling approach it is possible that students with prior interest may have responded, resulting in a respondent bias. Our modest sample size, for both the pilot and the survey is acknowledged as a limitation. The use of survey as a data collection method may have limited the depth of our results but did provide breath of response. Depth would be provided using further research with qualitative methods to elicit more detail responses. Proposed qualitative investigation should explore N\&D students' familiarity with, views of, attitudes towards and agency for future sustainability needs, as well as use of sustainability related concepts. Despite these limitations, this paper is the first known study to report on student N\&D familiarity and perceived importance of sustainability. This highlights opportunities as well as the need to embed these concepts in future higher education curricula to equip future N\&D professionals to contribute towards attaining sustainable development goals.

Author Contributions: Conceptualization, S.B. and J.M.; methodology, S.B., J.M., M.V., T.A.; formal analysis, S.B., J.M.; investigation, S.B., J.M.; data curation, S.B., J.M.; writing-original draft preparation, S.B., J.M.; writing-review and editing, S.B., J.M., M.V., T.A.; project administration, S.B., J.M.; funding acquisition, S.B., J.M., M.V., T.A. All authors have read and agreed to the published version of the manuscript.

Funding: This research was funded by a University of the Sunshine Coast Learning and Teaching Exploratory Grant.

Acknowledgments: The authors would like to acknowledge the assistance of Tetyana Rocks who contributed to the initial search for literature.

Conflicts of Interest: The authors declare no conflict of interest. The funders had no role in the design of the study; in the collection, analyses, or interpretation of data; in the writing of the manuscript, or in the decision to publish the results. 


\section{References}

1. Wilkins, J.L.; Lapp, J.; Tagtow, A.; Roberts, S. Beyond Eating Right: The Emergence of Civic Dietetics to Foster Health and Sustainability Through Food System Change. J. Hunger Environ. Nutr. 2010, 5, 2-12. [CrossRef]

2. Harmon, A.; Lapp, J.L.; Blair, D.; Hauck-Lawson, A. Teaching Food System Sustainability in Dietetic Programs: Need, Conceptualization, and Practical Approaches. J. Hunger Environ. Nutr. 2011, 6, $114-124$. [CrossRef]

3. Renouf, J.S.; Mann, M.E.; Cook, J.; Wright, C.; Steffen, W.; Nunn, P.; Dube, P.; Jouzel, J.; Lewandowsky, S.; Poelina, A.; et al. Why Universities Need to Declare an Ecological and Climate Emergency? 2019. Available online: https://www.timeshighereducation.com/blog/why-universities-need-declare-ecological-and-climateemergency (accessed on 9 January 2020).

4. Kagawa, F. Dissonance in students' perceptions of sustainable development and sustainability. Int. J. Sustain. High. Educ. 2007, 8, 317-338. [CrossRef]

5. Bollani, L.; Bonadonna, A.; Peira, G. The Millennials' Concept of Sustainability in the Food Sector. Sustainability 2019, 11, 2984. [CrossRef]

6. Sidiropoulos, E. The personal context of student learning for sustainability: Results of a multi-university research study. J. Clean. Prod. 2018, 181, 537-554. [CrossRef]

7. Desha, C.; Hargraves, K. Higher Education and Sustainable Development: A Model for Curriculum Renewal; Routledge: New York NY, USA, 2014.

8. Filho, W.L. Sustainability and University Life. Int. J. Sustain. High. Educ. 2000, 1. [CrossRef]

9. Lockie, S. Post-truth politics and the social sciences. Environ. Sociol. 2016, 3, 1-5. [CrossRef]

10. Worsley, A.; Droulez, V.; Ridley, S.; Wang, W.C. Dietitians' Interests in Primary Food Production: Opportunities for Greater Involvement in the Promotion of Environmental Sustainability. J. Hunger Environ. Nutr. 2014, 9 , 64-80. [CrossRef]

11. Mintz, K.; Tal, T. The place of content and pedagogy in shaping sustainability learning outcomes in higher education. Environ. Educ. Res. 2018, 24, 207-229. [CrossRef]

12. Robertson, J. The Sane Alternative; Spring Cottage: Ironbridge, UK, 1983.

13. Hawkins, I.W.; Balsam, A.L.; Graves, D. A Qualitative Study of the Skills That Enabled the Pro-Environmental Behaviors of Registered Dietitians. J. Hunger Environ. Nutr. 2015, 10, 60-71. [CrossRef]

14. Zepke, N.; Leach, L. Improving student engagement: Ten proposals for action. Act. Learn. High. Educ. 2010, 11, 167-177. [CrossRef]

15. Knowles, M. The Adult Learner: A Neglected Species; Gulf Publishing: Houston, TX, USA, 1984.

16. Carino, S.; McCartan, J.; Barbour, L. The Emerging Landscape for Sustainable Food System Education: Mapping Current Higher Education Opportunities for Australia's Future Food and Nutrition Workforce. J. Hunger Environ. Nutr. 2019, 1-22. [CrossRef]

17. Cotton, D.R.E.; Warren, M.F.; Maiboroda, O.; Bailey, I. Sustainable development, higher education and pedagogy: A study of lecturers' beliefs and attitudes. Environ. Educ. Res. 2007, 13, 579-597. [CrossRef]

(C) 2020 by the authors. Licensee MDPI, Basel, Switzerland. This article is an open access article distributed under the terms and conditions of the Creative Commons Attribution (CC BY) license (http://creativecommons.org/licenses/by/4.0/). 